\title{
LIBERTAD, SOCIEDAD, ECONOMÍA Y EDUCACIÓN: CUÁLES SON PRIORIDADES EN EL PERÚ
}

Entrevista a Luis Solari, ex Primer Ministro del Perú

Silvia Caironi y Paolo Bidinost

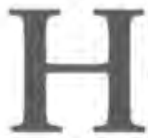

oy en día, tanto en Europa como en América Latina, existe una posición muy contradictoria respecto de la libertad: por un lado, un miedo de la libre iniciativa económica y social de la gente (el libre mercado es el diablo) y un miedo hacia la pertenencia de las personas a realidades sociales e ideales (parece que todas las pertenencias son en el fondo sectarias y mafiosas); por otro, una confianza ingenua e ilusoria en la libertad de la ciencia y una idea muy ambigua de libertad de prensa. ¿Qué opina al respecto?

El problema que hay en este momento sobre la libertad en la región y en el mundo está vinculado con la pérdida de espacio de la educación humanista. Se podría graficarlo compararivamente al señalar la diferencia entre América Latina, que es el paraíso de la inequidad, y la Unión Europea, que es el paraíso de equidad. La Unión Europea fue construida por humanistas, Schumann y diversos exponentes del personalismo, como Rougemont, cuyos colaboradores también eran humanistas; ellos crearon una estructura que primariamente tenía que atender a las personas y sus necesidades y proteger sus derechos fundamentales. Este fue el camino. Hoy en día lo que está sucediendo en la Unión Europea es una pugna entre 
los humanistas, que la construyeron, y los utilitaristas. Los utilitaristas tratan de poseer el espacio público y logran este objetivo afectando el lugar donde se reproduce el sentido comunitario y la solidaridad, que es fundamentalmente la familia, y el más intangible de los cuerpos sociales, es decir, la fe religiosa. En efecto, no solamente se trata de posiciones anticristianas, sino también antijudías y antiislámicas, tres religiones que tienen posiciones muy claras sabre el sentido del bien, la moral, la familia, la libertad, etc.

El espacio de la globalización ya no es territorial, sino supraterritorial. Esta nueva pugna, a partir de la caída del muro de Berlín, ha llegado también a América Latina. Los utilitaristas que construyeron América Latina lo hicieron en provecho propío y desatendiendo las necesidades de las personas y sus derechos. El escenario es el siguiente: donde las cosas de la vida se habían mantenido más o menos amalgamadas con la fe, la solidaridad, el sentido de la familia y de la unidad, súbitamente, los utilitaristas tratan de afectar la fe, la familia y la solidaridad. Lo que sucede actualmente en América Latina es una combinación de esta pugna más diversos factores adicionales; el más importante de ellos es la resultante del choque entre dos vectores: de un lado, la estructura construida por los utilitaristas, que permanentemente genera desigualdades e insatisfacción de necesidades y conculcación de derechos; de otro, la persona, que creo nunca ha sido tan consciente de su ser como en este inicio del siglo xxa. Otros factores que obviamente han contribuido con este proceso son la velocidad de transmisión de la información, el incremento de la movilización de personas y, por supuesto, cincuenta ańos de cultura de derechos humanos, que ha permitido que aparezca una generación de defensores de la persona.

$\mathrm{La}$ "crisis de la libertad" se origina en esta complejidad que empuja a muchos a separar la vida-coridiana de su vida de fe, Definitivamente, creo que no es una situación creada por el azar, sino que hay grupos interesados en esa separación con estrategias definidas 
LIBERTAD, SOCIEDAD, ECONOMÍA Y EDUCACIÓN,

CUÁLES SON PRIORIDADES EN EL. PERÚ

en ese sentido, quizá mejor percibidas en esta parte del mundo, donde la familia y la religiosidad son componentes muy importantes de la diversidad cultural.

¿Está de acuerdo con la afirmación de que el neoliberalismo y la economía de mercado han sido un fracaso en América Latina?

Por las razones expresadas antes, no estoy de acuerdo cuando se dice que lo que sucede en América Latina ha sido causado por el fracaso del neoliberalismo y que todo se reduciría a cambiar el modelo económico. ¡ No, eso es una parte del problema, pero hay otras razones! Cuando uno dice el fracaso del neoliberalismo, en realidad, está diciendo que los planes de los utilitaristas para América Latina han fracasado. Esto es lo que al final ha fracasado, pues el neoliberalismo per se no era capaz de producir lo que ha sucedido hoy en día.

No tiene nada que ver con el neoliberalismo, entre otros, el hecho de que en América Latina se escuche con atención las recomendaciones de funcionarios de organismos internacionales y multilaterales para nuestros países, muchas veces sin el conocimiento integral o estructural de nuestras realidades. Cuando uno pregunta, por ejemplo, a algunos acerca de economía territorial o de demografía económica de nuestro país, este tema es prácticamente desconocido. Además, se dice que la prioridad debe ser la educación, pero, en realidad, hay un problema gravísimo que es que los pobres se mueren más que otros grupos por ser pobres, lo que determina que lo prioritario es darles cobertura gratuita de salud. Uno no puede enseñarle a un niño muerto, lo primero que se tiene que hacer cuando hay pobreza es evitar que los pobres se mueran y si se evita que los nif́os pobres se mueran, cuando llegan a la edad apropiada se les brinda educación.

Este tema es parte del verdadero problema, que es que los pobres ganan por debajo de lo que necesitan para vivir dignamente y 
esa brecha tiene que ser cerrada a la brevedad; nadie habla de este terma. El gasto social, para cerrar esa brecha, no se puede focalizar porque los programas sociales no son nominales (no son listas de personas con direcciones y ubicación ciertas). ¿Qué organismo internacional o multilateral está invirtiendo en convertir esos programas en nominales? ¿Habla algún organismo de la desigualdad territorial —al interior de los países- que se ha producido en la región como consecuencia de la integración comercial? Obviamente, se toman decisiones y no se tiene en cuenta la realidad global del país. Esto no se relaciona con el modelo económico, sino con la visión de compartimentos o sectores del racionalismo contemporáneo.

Mientras mantengamos a los países de la región con economias territorialmente concentradas se seguirán teniendo dos patses al interior de cada país. Esta es la piedra angular del origen de las desigualdades y de otros problemas estructurales más complejos, que no se corregirian con un eventual cambio de modelo económico.

Se estudia poco la propia realidad estructural y se habla mucho de la realidad. Después se repite el fracaso del neoliberalismo, pero el problema no es ese, el problema es que se toman decisiones sin mirar a la realidad íntegra de la estructura. ¿Por qué razón a un gerente de una multinacional que toma decisiones sin mirar a la realidad lo despiden, $y$ a un funcionario internacional o nacional que toma decisiones fuera de la realidad y que gasta millones de dólares y obtiene pobres resultados, no lo despiden? La responsabilidad es una expresión de la solidaridad; la pérdida de esta como estandarte de la conducta social es uno de los más graves problemas en la gestión pública. Del utilitarismo nace la corrupción, las dictaduras y el eugenismo, que han sido actores protagónicos en nuestros paises. Entonces, el problema no termina siendo una doctrina económica, sino que incluye la naturaleza de las personas que la aplican. 
¿̨i este es el problema general, en la parte social cuál viene a ser el mayor problema?

El mayor problema en la parte social es que la estructura genera permanentemente una brecha entre los ingresos y el gasto que requieren los pobres para vivir dignamente o gasto corriente o canasta básica o esencial. Por tanto, la solución es cerrar rápidamente esa brecha $y$, simultáneamente, generar los cambios en la estructura que produce esa injusticia, para que no la siga produciendo. Esto significa servicios de salud gratuitos para los que no los pueden pagar. La calidad de la educación tiene cuatro componentes conocidos -infraestructura, curriculo, capacitación de maestros y material educativo-, el que afecta directamente el bolsillo de los pobres es el material educativo, por tanto, debiera proveérsele útiles y textos en forma gratuita, así como calzado y uniforme. No se debe tener a los pobres obligados a dejar de comer tres panes para comprar un lápiz o dejar una comída para comprar un cuaderno. Es indispensable cubrir esa brecha hasta que el pobre se convierta en generador de bienes, además de receptor de servicios, o mejore su calidad laboral y sus ingresos puedan cubrir su canasta básica.

Ordenar el gasto social tiene una gran herramienta: convertir los programas sociales en programas nominales. La forma más efectiva es avanzar rápidamente en la cobertura gratuita de salud de los pobres; automáticamente, ello genera un listado nominal y domiciliado de pobres, con el cual se puede administrar y focalizar mejor los demás programas. 
Una objeción dice que es imposible cerrar la brecha de la pobreza para la mitad subdesarrollada del país y, al mismo tiempo, seguir con las políticas sociales para la otra mitad, aquella desarrollada. ¿Qué contesta?

Esta es la posición de los que poseen visión sectorista de la solución de los problemas de un pais, de los que creen que la solución al problema de la pobreza está en los programas sociales. Lo graficaré con un ejemplo; en el Perú, el $75 \%$ de las provincia son rurales, poseen una pobreza de $68 \%$ y el $77 \%$ de las unidades productivas son micro y pequeñas empresas rurales, pero menos del $3 \%$ de estas empresas participan en las exportaciones. ¿Cómo creen los sectoristas de las políticas sociales resolver la pobreza de estas personas si no incorporan esas unidades productivas a los mercados externos y no cambian su modalidad productiva? Aliviar la pobreza se puede hacer con programas sociales; superar la pobreza se consigue modificando los ingresos de los pobres, mediante la creación de nuevas oportunidades económicas para ellos. Esto último no se puede hacer sin aplicar un enfoque diferenciado a los territorios de una nación.

Las desigualdades no solo son sociales y económicas, sino que se desarrollan en territorios concretos. Por lo que la concepción implícita de la pregunta debe ser ampliada a que los problemas estructurales se pueden aliviar con acciones sectoriales, pero solo pueden ser erradicados con soluciones estructurales y que estas requieren un enfoque territorial para soluciones territorialmente individualizadas.

Por ejemplo, un maravilloso instrumento para la equidad y la justicia en una nación es la descentralización. Sin embargo, la descentralización peruana se ha convertido en un proceso administrativo, a pesar de que debe apuntar a ser un proceso esencialmente humanista. Así, aunque han sido mejorados los criterios 
de distribución del canon minero, este solo puede ser utilizado para infraestructura, en territorios donde la gente no tiene para cubrir sus gastos en nutrición, salud o educación. Entonces, es indispensable que la ley del canon se modifique para que esos recursos puedan ser utilizados, antes que nada, en la protección de esos derechos sociales. Lo que la gente necesita es justicia. Entonces necesitamos convertir a todos los actores de la descentralización en humanistas, necesitamos que la descentralización tenga una clara acción humanista.

¿Cómo esto impacta la misión y la responsabilidad de una universidad? ¿Cuál es la prioridad de la educación hoy en día?

La educación escolar es básicamente adquisición de información y construcción de método; la universidad, además de la cuestión formativa, debería moldear la capacidad creativa de la persona mediante un aprendizaje para crear el futuro, pero con una visión impecablemente humanista. Esto crea una nueva misión: qué realidad va a ser moldeada con un nuevo futuro, la de los tecnócratas sectoristas o la que expresa la verdad objetiva. No es cierto que el Perú esté sobre estudiado; en qué universidad se enseña economía territorial o geografía económica, o creación de futuros o demografía económica. Acaso no escuchamos cotidianamente que el aumento de las exportaciones automáticamente resuelve el problema del empleo. cuando, en realidad, es el desarrollo rural el mecanismo para reducir la sobre oferta de inano de obra en las grandes ciudades por migración. 
¿Conoce acaso usted que la integración comercial entre los países de la región ha aumentado la desigualdad territorial al interior de nuestros países porque se benefician solo los territorios que producen bienes? De este tema, ni se habla en el Perú, cuando ya ha tenido aquí y en México repercusiones político electorales.

Si tuviera que decidir la prioridad de la educación en una universidad, sin duda, escogería dos caminos: el primero, adaptar las diversas Facultades y Programas a la visión estructural y el enfoque territorial, para que formen de acuerdo con la realidad objetiva $y$ las verdaderas necesidades de los pueblos del Perú. Lo segundo, no menos prioritario, formar humanistas a carta cabal; gente joven dispuesta a vivir para los demás. La justicia no la pueden construir los urilitaristas; esta es tarea de los solidarios y justos.

La brecha económica Norte/Sur a escala mundial se refleja en Perú en una brecha Costa y Ciudades/Sierra y Selva. ¿Cuáles son las causas y cuáles las soluciones?

El principal problema de los países de la región es la existencia de una brecha territorial, Esta tiene varios aspectos: un aspecto urbano/rural, un aspecto costa/sierra-selva $y$, el más importante, territorios productivos/territorios poco productivos.

Esta situación se ha producido básicamente por un proceso de concentración del aparato productivo en pocos territorios de un país; esto determinó la concentración de la población en esos territorios y la consiguiente concentración del presupuesto público en los mismos, al serla distribución de este fundamentalmentepor densidad demográfica. Esta situación ha generado dos paises al interior de nuestras naciones. La Corporación Andina de Fomento, en su Reporte de Economía y 


\section{LIBERTAD, SOCIEDAD, ECONOMIA Y EDUCACIÓN:}

CUÁLES SON PRIORIDADES EN EL PERUU

Desarrollo 2005, ha demostrado que la integración comercial entre nuestros países ha aumentado la desigualdad territorial al interior de ellos.

Esta situación ha empeorado debido a que desde 1997 el flujo de capitales hacia la región es cada vez menos importante en nuestro crecimiento económico, habiendo sido sustituida en ese fin por la demanda de nuestras exportaciones. Obviamente, esto ha beneficiado a los territorios productores, aumentado la desigualdad con los territorios que intervienen poco en la producción para el comercio exterior.

Las soluciones son básicamente dos, esencialmente estructurales. Primero, descentralización económico-productiva con la consiguiente redistribución de la población en nuestro territorio patrio y la subsiguiente redistribución territorial de los ingresos y el presupuesto público. La segunda, generar una agresiva política de desarrollo de consorcios exportadores a partir de las micro y pequeñas empresas (Mypes), que constituyen el $98 \%$ de nuestras empresas, además de que el $77 \%$ de nuestras empresa son Mypes rurales. Este segundo camino es esencial para el primero y genera inclusión económica, formalización de la mayoría de las empresas, fiscalización de mayoristas y acopiadores, incremento de aportantes a los fondos de pensiones y la seguridad social, nuevo mercado crediticio y nuevo mercado interno de consumidores, así como el incremento de la participación de las Mypes en la generación del Producto Bruto Interno, Existen otras, pero me quedo con estas dos por su alto impacto en la modificación de las relaciones económicas, sociales y políticas del Perú, para la instauración de una justicia social que territorialmente alcance a todos. 
¿Hay una alternativa entre una pura economía de mercado y un subsidio permanente? ¿Existe un modelo económico original del Perú y de América Latina?

Vuelvo a la primera respuesta. Si los aparatos estatales estuvieran administrados por humanistas, ¿estaríamos en la situación actual? Creo que no. El problema esencial es ese. Por eso, la función esencial de una universidad, sobre todo si se considera católica, es formar humanistas y si los forma para la gestión pública, mejor.

El camino consiste básicamente en rehacer la estructura que genera injusticia. Para esto, es indispensable aplicar a cada país una matriz de análisis estructural en sus componentes económico y productivo, demográfico y de presupuesto público, para establecer las dinámicas en el tiempo y poder generar las soluciones para cada país. Obviamente, con una claridad absoluta en que deben ser identificados los caminos para la inclusión rápida de los pobres en los servicios, la toma de decisiones y la economía, la producción y los mercados.

No es un problema de modelos ni subsidios; es un problema de estructura en cada país, que genera injusticia y diversas asimetrías. Lo que sucede es que las dinámicas económicas internacionales postcaída del muro de Berlín están acentuando las asimetrías que dependen de las características peculiares de la estructura de cada país. No olvidemos que esencialmente el problema se origina en la alta concentración productiva en pocos territorios que tienen en su interior los paises de América Latina.

No puedo dejar de mencionar que hay paralelamente a ese curso de los acontecimientos un desarrollo excepcional de conciencia personal en la gente, que determina un rechazo creciente a la estructura o sistema, lo que ya ha ocasionado procesos electorales con evidente confrontación territorial. Esto revela que no podemos seguir más 
como rabdomantes en la región, buscando nadie sabe qué, sino aplicar rápidamente soluciones estructurales a los problemas estructurales.

Ya pasamos por el proyectismo de los setenta y los ochenta $y$ también por las reformas sectoriales de los noventa y nada cambió; las cosas empeoraron. Ya es suficiente. Sí, creo que es hora de generar nuestras propias soluciones y que no nos den más receras de fuera, que demostradamente han servido para acentuar la injusticia.

¿Qué significa que la persona es el centro y protagonista del desarrollo y del crecimiento económico, político, social y cultural?

Significa que vivimos en el presente, pero existimos para el futuro. Cada decisión que tomamos en el ejercicio de nuestra voluntad y libertad, no es para el momento, sino para el tiempo siguiente. Tener claro este concepto nos impulsa permanentemente a ser actores protagónicos de la historia y de nuestra propia historia personal y familiar. El ejercicio de las capacidades de crear y amar es inseparable. No se crea el futuro para uno solo, sino para todos, y los otros, a su vez, para los demás y así sucesivamente.

Es una conducta y un proceso inevitables en la construcción de la justicia. Sin embargo, debo señalar que no todos se comprometen con ella. Por eso, he mencionado que la construcción de la justicia requiere en la región la formación de justos, que se vean a sí mismos en los demás y obren con convicción en la búsqueda constante del bien para los demás, que realmente conviertan a la persona en objetivo central de nuestros países. 
ENTREVISTA A LUIS SOLARI

¿Qué significan en la realidad política y social del Perú y de América Latina los tres principios no negociables indicados para el Papa (respecto de la vida, promoción de la familia, libertad de educación)?

Significa que Benedicto XVI conoce perfectamente por dónde viene el impacto de la globalización en su pretendido intento de deshumanizar a la humanidad y de desnacionalizar a las naciones.

Quien desprecia la vida, rechaza con ello a todos los demás; quien compromete a la familia, recusa el lugar donde se aprende la solidaridad y la propia nacionalidad; quien no defiende la libertad de educación, se somete al Estado y al poder transitorio que lo conduce $y$ abdica al ejercicio de su libertad de pensamiento $y$ a su rol formador del futuro.

Vivir solo para uno mismo, sin ejercicio de la solidaridad, considerando la nacionalidad como algo secundario y renunciando a la formación de quienes serán parte del vaso social que contiene a una nación, abre las puertas al llamado pensamiento único. Creo en la diversidad, la solidaridad, en ser para los demás, en la nacionalidad, en suma, creo en la humanidad y su capacidad para crear un mejor futuro; sí, a pesar de las guerras, creo en la fraternidad, no creo en los intereses mezquinos que las promueven.

Definitivamente, los principios enunciados son no negociables y deben convertirse, especialmente en América Latina, en estandartes de esta nueva batalla en la que nos encontramos; ¿quiénes están en favor de la persona y quiénes están en contra de ella?

Veo con preocupación que ciudadanos de nuestros países constituyan organizaciones que reciben financiamiento para predicar en contra de valores esenciales en la marcha de nuestras naciones. Estas son las nuevas alianzas sociales que leí en un documento de 1993, precisamente acerca de la caída del muro de Berlín, para 


\section{LIBERTAD, SOCIEDAD, ECONOMIA Y EDUCACIÓN:}

CUÁLES SON PRIORIDADES EN EL PERÚ

vencer la resistencia organizada — como planteaba el documento-, refiriéndose obviamente a quienes están dispuestos a levantar y defender esos estandartes. 